\title{
Ethos e cenografia da Voice for Men - Brasil: uma exploraçao do discurso intimidatório na internet
}

\author{
Ethos and scenography of a Voice for men - Brazil: an exploration of \\ online intimidating discourse \\ Juan Manuel López-Muñoz ${ }^{1}$ \\ Tamiris Machado Gonçalves² \\ 1 Universidad de Cádiz, Cádiz, Espanha. \\ ${ }^{2}$ Pontifícia Universidade Católica do Rio Grande do Sul, Porto Alegre, Rio Grande do Sul, Brasil.
}

\begin{abstract}
Resumo: Dando continuidade ao debate sobre os discursos intimidatórios na internet, este artigo analisa o ethos discursivo e a cenografia do endereço eletrônico $A$ voice for Men Brasil - AVfM. A metodologia proposta, em que vários elementos verbais e não verbais foram levados em consideração, permite identificar um simulacro de ethos de contrapúblico subjugado que perpetua estereótipos, acentuando as diferenças de gênero, e pode incitar o ódio contra o sexo feminino, mais especificamente contra as mulheres feministas.
\end{abstract}

Palavras-chave: análise de discurso; discursos intimidatórios; web; ethos; cenografia.

\begin{abstract}
Contributing to the debate on online intimidating discourses, this article analyzed the discursive ethos and scenography of the web $A$ voice for Men Brazil - AVfM. The analyzed data, where several verbal and non-verbal elements were taken into account, allows us to identify a simulacrum of subjugated counter-public ethos that perpetuates stereotypes, accentuates gender differences, and could incites hatred against the female sex, more specifically against the feminist women.
\end{abstract}

Keywords: discourse analysis; intimidating speech; web; ethos; scenography.

\section{Introdução}

Em razão da cisão histórica existente entre as proposições feministas e sua luta contra o machismo - e tendo em conta toda a carga de discursos de intimidação envolvida em enunciações dessa natureza -, este artigo analisa a página web $A$ voice for Men Brasil - AVfM, mais especificamente a aba missão, a fim de entender o papel que esse site, autodeclarado portavoz do Movimento por Direitos Humanos de Homens e Meninos, desempenha no debate sobre a igualdade de gênero .

Para levar a cabo as análises, recorremos aos conceitos de ethos discursivo, de Maingueneau (1997, 2004); identidade social e discursiva, de Charaudeau (2017); valoração, de Volóchinov ([1929] 2017) e Bakhtin ([1920-24] 2012); e discurso intimidatório, de López Muñoz e Capponi (2017).
Adaptando-se as palavras de Venturini e Scherer (2017, p. 164) ao contexto desta investigação, pode-se dizer que pensar sobre discursos intimidatórios no âmbito virtual é "um nó desafiador" porque implica considerar imagens discursivas, cenas enunciativas, elementos linguísticos e não linguísticos, aspectos sociais, culturais. Cientes do desafio existente, este artigo visa a dar continuidade às pesquisas sobre discursos de intimidação, colocando-se a tarefa de pensar como eles se apresentam na modalidade digital; quais suas características; em que medida a internet configura-se como espaço propício a práticas discursivas dessa natureza.

\section{Pensando o discurso intimidatório no âmbito digital}

A Linguística como área de estudos está em constante renovação. Dado que seus estudos focalizam 
diversos pontos do grande fenômeno que é a linguagem, essa ciência cresce tanto interna quanto externamente, com áreas que com ela se propõem ao diálogo, como a filosofia, o direito, a sociologia e a comunicação, por exemplo.

A análise do Discurso pode ser considerada um dos vieses internos da Linguística, uma disciplina de entremeio (DEZERTO, 2010), cujo interesse repousa, conforme Bonnafous e Krieg-Planche (2013), sobre formas e modalidades que deixam ver o discurso social. Segundo essas autoras, a análise do discurso possui a particularidade de estar entre as ciências da linguagem e outras ciências humanas, preocupando-se em compreender a relação entre produção discursiva e linha social, a partir de dispositivos enunciativos específicos.

Sobre essa temática, Charaudeau e Maingueneau (2018, p. 143) explicam que aquilo que é entendido como análise do discurso é um composto de diferentes faces: estudos retóricos, filológicos, hermenêuticos, textuais, pragmáticos, etnográfico-comunicacionais. Para eles, ainda há a contribuição de pensadores "como Foucault, que desloca a história das ideias para o estudo dos dispositivos enunciativos", e de Bakhtin, de quem advém a "dimensão axiológica da atividade discursiva".

Independentemente das relações que façamos, analisar discursos é pensá-los circunscritos a uma conjuntura, entendendo-os atravessados por uma história, uma valoração; vindos de alguém, indo para alguém, saídos de um espaço, interpelados por possibilidades de sentidos. Analisar discursos não é procurar o ideal, o gramaticalmente aceito, é entender o que está posto, como está posto e por que o está (SOUSA, 2014).

Paveau (2015) sublinha que especificamente em relação à análise de discursos digitais surge um quadro de questionamento das metodologias linguísticas, uma vez que o universo on-line faz questionar os papéis da linguagem no sentido de repensar seus produtores e destinatários, bem como seus elementos constitutivos. Segundo a autora, a linguística atual não pode dizer muito sobre o universo de tecnopalavras (URL, hasthtag) por isso problematiza:

[...] o que pode a descrição linguística de um URL, uma hashtag, um sinal digital, uma imagem macro, exceto separar os elementos de acordo com sua semiose (texto de um lado, imagem de outro, e codificar um terceiro) e desfazer isso que é precisamente a sua especificidade, isto é, a sua co-constituição estrutural? (PAVEAU, 2015$, p. 13$)^{1}$

\footnotetext{
1 Tradução nossa para o trecho: "[...] que peut dire la description linguistique d'une URL, d'un hashtag, d'une pancarte numérique, d'une image macro, sauf à séparer les éléments selon leur sémiose (texte d'un côté, image de l'autre, et code d'un troisième) et à défaire par conséquent ce qui fait justement leur spécificité, c'est-à-dire leur coconstitution structurelle?".
}

Sua proposição apresenta a ideia de que é necessário construir métodos de análise condizentes com a realidade dos discursos que se analisa em âmbito virtual. Isso em razão de que:

Os discursos nativos da web também são relacionais: a arquitetura da rede torna-os todos materialmente inter-relacionados, entre eles e seu enunciador, o que lhes confere propriedades particulares como sua investigabilidade (qualquer declaração on-line pode ser pesquisada e encontrada através de ferramentas de pesquisa, como motores) e sua idionumericidade (qualquer declaração on-line da web tem um formulário único e subjetivo, determinado pelos parâmetros de navegação, sociabilidade, leitura e escrita do usuário). A Linguística possui em sua bagagem teórica a noção de dialogismo e seria tentador aplicálo à relacionalidade dos discursos digitais nativos; mas on-line a relacionalidade é material e automática, e não depende de marcas de intertextualidade ou analogias da competência interpretativa do analista (ibidem, p. 15) ${ }^{2}$.

Frente a esse argumento, Paveau (2015, 2011, 2009) defende que analisar discursos digitais deve considerar uma linguística simétrica, em que os elementos em análise sejam visualizados em perspectiva de contribuição, de relação, e não sob o ponto de vista binário tradicional da linguística de outros tempos. Em sua visão, uma linguística simétrica abarcaria elementos linguísticos e não linguísticos a partir da ideia de um continuum entre materialidades de linguagem e ambientes de produção. Nesses termos, permite o diálogo entre áreas, a fim de contemplar os fenômenos focalizados sob um viés multifacetado.

Nesse sentido, a análise do discurso viabiliza, por sua característica de intersecção e diálogo, problematizar métodos para analisar discursos intimidatórios na internet, mais especificamente em páginas de difusão de conteúdo. É oportuno sublinhar que analisar sítios on-line que deixem ver projeção de discurso intimidatório requer que, de antemão, o pesquisador selecione o escopo de atuação e por ele procure.

Fenômeno complexo, para López Muñoz e Capponi (2017, p.10), discursos intimidatórios são aqueles que

\footnotetext{
2 Tradução nossa para o trecho original: "Les discours natifs du web sont par ailleurs relationnels: l'archi-tecture du réseau fait qu'ils sont tous matériellement interreliés, entre eux et à leur énonciateur, ce qui leur donne des propriétés particulières comme leur investigabilité (touténoncé en ligne peut être cherché et trouvé via des outils de recherche comme les moteurs) et leur idionuméricité (tout énoncé du web en ligne possède une forme unique et subjective, déterminée par les paramètres de navigation, de sociabilité, de lecture et d'écriture de l'internaute). La linguistique possède dans ses bagages théoriques la notion de dialogisme et il serait tentant de l'appliquer à la relationalité des discours numériques natifs, mais en ligne, la relationalité est matérielle et automatique, et ne dépend pas de marques d'intertextualité ou d'analogies issues de la compétence interprétative de l'analyste".
} 
apresentam carga de ameaça, ódio ou discriminação. Trata-se de:

[...] uma prática discursiva formalmente ampla e heterogênea, caracterizada pela intenção de potencializar as tensões existentes entre determinados grupos sociais ou demográficos, através de estratégias que abarcam desde reafirmação identitária de pertencimento ao grupo dominante até a geração de insegurança ou de medo no grupo dominado, mais do que como uma mera forma de expressão da violência verbal entre indivíduos ${ }^{3}$ (LÓPEZ MUÑOZ; CAPPONI, 2017, p. 10).

Essa prática discursiva a qual se referem os autores é, também para eles, tecida em uma complexa malha formada por elementos linguísticos, discursivos e pragmáticos, que se atualiza quando da enunciação entre sujeitos concretos. Estão, portanto, incrustados no âmago das relações humanas e desse lugar devem ser analisados a fim de entender a camada sócio-histórica que os reveste.

Fernández Smith (2017) explica que os discursos intimidatórios são práticas discursivas nas quais se pode ver uma teia de relações gramaticais, lexicais, pragmáticas e sociodiscursivas, que são a manifestação de uma materialidade. Potencialmente dirigida ao público geral quando se encontra nas comunicações públicas, está pronta a atingir quem nelas se veja. $\mathrm{O}$ autor menciona que intenção e aceitabilidade seriam critérios implicados na interpretação desses discursos, já que a relação entre autor-destinatário terá lados explícitos e implícitos na elaboração daquilo que se quer comunicar para um alguém projetado na enunciação em que terá lugar o discurso intimidatório. Tais relações são por Fernández Smith explanadas na elaboração que segue.

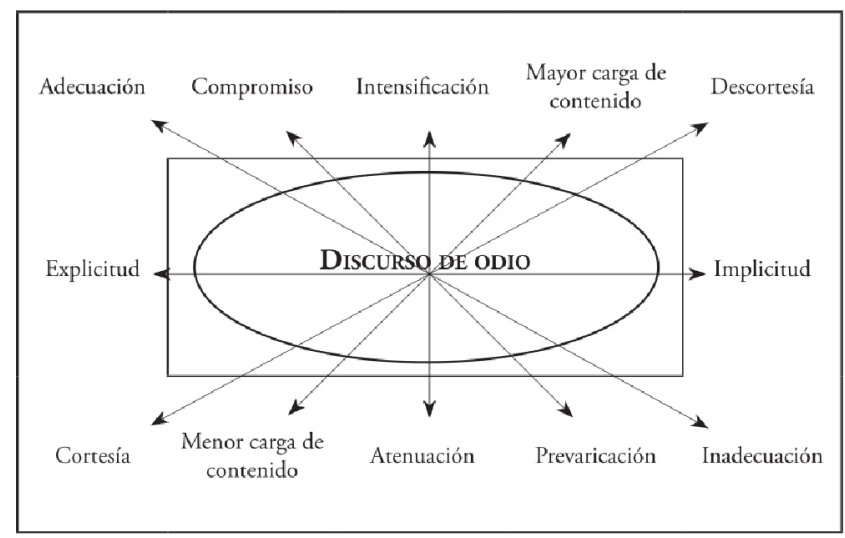

Fonte: Fernández Smith (2017).

\footnotetext{
3 Tradução nossa para o trecho original: "[...] una práctica discursiva formalmente amplia y heterogénea caracterizada por la intención de potenciar las tensiones existentes entre determinados grupos sociales o demográficos, a través de estrategias que abarcan desde la
}

Nessa complexa construção, há, ainda, componentes que tencionam liberdade de expressão e manifestação de discursos de ódio, este tocando questões jurídicas porque tipificados, por exemplo, em leis, como crime, porque envolve delito.

$\mathrm{Na}$ identificação dos discursos intimidatórios digitais, há a problemática ensejada pelo ciberespaço, em que há certa dificuldade em nomear aos praticantes desse tipo de discurso, em razão da possibilidade de esconder-se em perfis anônimos ou edificados com base em personagens adotados nesse contexto ou ainda porque estejam protegidos pelo título de determinado fórum ou site. Nesse caso, quem analisa o discurso intimidatório digital pode valer-se dos conceitos de ethos discursivo e identidades sociais e discursivas para levar a cabo suas explanações. Além disso, pode analisar a materialidade do discurso digital a partir das valorações que atravessam seus elementos verbais, visuais, contextuais, históricos, éticos e estéticos a fim de encontrar os fios que tecem as possibilidades de sentidos para o que está posto.

O conceito de ethos discursivo (CHARAUDEAU; MAINGUENEAU, 2018), refere-se à imagem de si construída via discurso por um locutor para seu interlocutor. É uma construção em permanente processo de edificação, reelaboração e ajustes. Essa construção parte de um modelo de imagem anterior, já estabelecida por rituais e rotinas de interação social, nas quais o interlocutor atribui ao locutor referências com base em um status social reconhecido. O ethos se constrói e se interpreta, portanto, a partir de modelos sociais disponíveis, que são ajustados no momento da interação, em função dos objetivos perseguidos e das condições de produção, que determinam o léxico, os temas, as maneiras de dizer e os papéis dos participantes. Cada uma das variações realizadas sobre o modelo preestabelecido é avaliada, tanto pelo locutor como pelo interlocutor, como eleições encaminhadas à caracterização de um ethos singular adequado à situação de comunicação, em um jogo dialético entre diferenças e conformidades sociais (SOULEZ, 2002, p. 179).

A partir do ethos é que se mostra o carácter moral do locutor (suas intenções e sua personalidade como locutor) na relação com o interlocutor. No discurso mediado por computador, o ethos cumpre um papel fundamental, dada a ausência das informações identitárias que a interação direta comumente oferece. Seja como for, ele manifesta a defesa de um ponto de vista, com a finalidade de obter algo. Tem por natureza um carácter público: é o que o locutor quer mostrar sobre si mesmo

reafirmación identitaria de pertenencia al grupo dominante hasta la generación de inseguridad o de miedo en el grupo dominado, más que como una mera forma de expresión de la violencia verbal entre individuos". 
ao interlocutor ou à audiência. Por outro lado, o ethos também deixa ver aspectos que fogem ao alcance do objetivo do locutor ou assume as formas de interpretação do interlocutor.

Nessa dinâmica, há de se sublinhar que o ethos não é a pessoa real que está falando, mas um avatar dessa, uma identidade conjuntural criada com conhecimento de causa - com objetivos a serem alcançados - no momento da fala, em um jogo de aceitação parcial ou completa dos modelos de identidades sociais preestabelecidos para uma comunidade de falantes. Resulta do posicionamento de locutor em relação ao que ele disse e em relação às convenções que regem a situação de comunicação. Tal posicionamento implica uma tensão constante entre desejos e intenções do locutor, por um lado, e limitações sociodiscursivas, por outro.

Essa dinâmica leva em consideração a cena enunciativa, isto é, a situação enunciativa como um todo: os espaços sociais nos quais uma dada comunicação se edifica, os gêneros discursivos que ela suscita, os parceiros comunicativos que estão postos em relação. É em termos gerais uma matriz de relações entre um eu e não eu (os outros: sujeitos, artefatos, discursos).

A cena enunciativa, segundo Maingueneau (2004, 1997), é dividida em três instâncias, a saber, cena englobante, cena genérica e cenografia. A primeira relaciona tipos de discursos a formatos de textos. Isso significa dizer que, ao acessar determinado texto, deve-se ser capaz de reconhecer os discursos constantes nele, isto é, ver um discurso religioso, político, didático. A cena genérica é caracterizada pelos gêneros discursivos. Isso porque a cada gênero discursivo correspondem, mais ou menos de forma estável, configurações pré-estabelecidas: locutor-interlocutor, suporte, rotinas linguageiras, tom, já que cada forma de interação se dá em gêneros específicos, que circulam em determinadas esferas e têm finalidades mais ou menos demarcadas socialmente. A cenografia, por sua vez, é instituída pelo próprio discurso porque é a representação em perspectiva. Charaudeau e Maingueneau (2018, p. 196; grifo dos autores) a descrevem como sendo ao mesmo tempo "aquilo de onde vem o discurso e aquilo que esse discurso engendra". Ela implica, pois, um momento, um lugar e certas escolhas dentro de uma gama de possibilidades limitadas em um determinado gênero discursivo. Tudo para validar a edificação de um discurso próprio mais ou menos ajustado aos moldes preestabelecidos.

Tendo em vista uma conjuntura sócio-histórica, o ethos surge da relação entre elementos de diferentes naturezas, linguística, ética, estética, física, social porque conta com a projeção que seu locutor tenta realizar. É mais um comportamento, "[...] que, como tal, articula verbal e não verbal, provocando nos destinatários efeitos multi- sensoriais" (MAINGUENEAU, 2004, p. 18). É, pois, uma maneira discursiva de comunicação que implica dizer e ser, harmonizando elementos de diferentes ordens para criar uma imagem que se tece no discurso via elementos que o compõem: a situação em si, o auditório, o tom de fala, as palavras, os gestos, a postura.

Embora o ethos seja construído a critério de seu locutor, resulta que a imagem pretendida pode não estar alinhada com aquela que, de fato, é produzida. Isso porque também deve ser considerado o esboço de representações que seu interlocutor já edificou em relação a ele. Daí o entendimento de que é um comportamento híbrido porque se trata de uma construção social e historicamente avaliada a existir em uma situação de comunicação circunscrita em uma determinada estrutura social (MAINGUENEAU, 2004, p. 16-20).

Ao encontro dessa conceituação, Amossy (2010) explica que o ethos seria uma imagem de si no discurso, que deixa ver facetas de identidade, aplicadas a pessoas ou grupos. Esse entendimento suscita tanto questões pertencentes à situação sobre a qual se edifica o discurso quanto àquelas anteriores a ele, como é o caso dos estereótipos, essas imagens cristalizadas que agrupam características e formam tipos, modelos, pré-construções para representações sociais (AMOSSY; PIERROT, 2010).

Neste ponto cabe pensar também nos conceitos de identidade discursiva e identidade social, de Charaudeau (2017). Na produção discursiva, entram em jogo a tensão entre as imagens que o locutor procura projetar de si mesmo e as imagens que a ele são atribuídas socialmente, sem que ele tenha algum poder de decisão sobre a ideia que seu interlocutor lhe sobrepõe.

Nessa dinâmica, a identidade social é atribuída pelo coletivo, é como um arcabouço de itens que andam junto a certas escolhas. Isso é inerente aos papéis sociais: ser pai requer certas posturas e não outras, certas atitudes e não outras, certo léxico, certos temas a serem abordados. Não é uma construção fixa, atemporal ou imutável, senão uma pré-construção no sentido de um conjunto de itens que são esperados quando se pensa em papéis socialmente desempenhados: pai, mãe, filho, professor, médico, político. É o conjunto de ações que se fizeram histórica e socialmente para saber que o papel de professor é aquele que não é o de outro ator social, por exemplo. Essas pré-delineações não dependem da vontade dos indivíduos porque são construções sociais variáveis segundo tempo e lugar.

A identidade discursiva, por outro lado, está vinculada ao constructo que o locutor cria no discurso e por meio do discurso. É, conforme Charaudeau (ibidem, p. 04), “[...] uma imagem de si mesmo (um 'ethos'), que serve estrategicamente à resposta à questão: 'como posso 
ser levado a sério"'4. Tendo isso em vista, são adotadas por parte do locutor atitudes para alcançar o que deseja: engajamento, neutralidade, parcialidade.

No entender das identidades e do ethos, convém suscitar o conceito de valoração, do Círculo de Bakhtin. Isso porque tais conceitos requerem o princípio de alteridade, que marca a relação eu-outro. Em sendo essa relação atravessada axiologicamente, cabe discorrer sobre valoração. Na teoria bakhtiniana, o entendimento do mundo se dá em relação a eu-outro; eu e outros eus; entre grupos sociais; a partir das instâncias discursivas em que estamos inseridos. Bakhtin ([1920-24] 2012) argumenta que não há verdades válidas em si, posto que tudo é atravessado emotivo-volitivamente, isto é, por juízos de valor, atrelados à relação ser-tempo-espaço, resultando na tomada de atitude (engajamento, passividade, parcialidade, desejo de parecer objetivo, racional ou neutro) frente aos mais variados temas.

Assim sendo, tudo tem um caráter axiológico, isto é, tanto nossa percepção quanto nossa ação estão atravessadas por valorações, que expressam sistemas de representação e de crença. Volóchinov ([1929] 2017, p. 95) afirma que "cada campo de criatividade ideológica tem seu próprio modo de orientação para a realidade e refrata a realidade à sua própria maneira". O que significa dizer que agimos a partir de um conjunto de valores: apreendemos e produzimos discursos atravessados por juízos de valor, que entram precisamente em cena no momento do cálculo das inferências ethóticas ${ }^{5}$.

A seguir, a partir dos conceitos arrolados, passamos ao entendimento do chamado Masculinismo um movimento que centraliza os direitos do homem. Analisaremos um endereço eletrônico que veicula ideias desse movimento, o site $A$ voice for Men Brasil.

\section{Masculinismo: o discurso que centraliza o homem}

Masculinismo, masculismo, hominismo ou androcentrismo são qualificações usadas para designar, desde distintos pontos de vista, um movimento cujo objetivo é promover a identidade masculina e debater acerca da problemática dos papéis sociais dos homens na sociedade contemporânea (WEST, 2000). Para DepuisDéri (2009, p.97), masculinismo é o termo empregado

\footnotetext{
4 Do original: "[...] une image de lui-même (un 'ethos'), qui l'entraîne stratégiquement à répondre a la question: 'comment puis-je être prisa au sérieux?'.

5 Usamos a expressão inferências ethóticas como um adjetivo derivado de ethos. De qualquer forma, esse uso pode ser atestado em Amossy, Ruth \& Marcel Burger (éds). 2011. SEMEN - Revue de sémio-linguistique des textes et discours 31, "Polémiques médiatiques et journalistiques. La discours polémique en question(s)". Disponível em: https://journals. openedition.org/semen/9050. Acesso em: maio 2018.
}

para fazer menção a "[...] um movimento social conservador ou reacionário, que afirma que os homens sofrem uma crise identitária porque as mulheres, em geral, e as feministas, em particular, dominam a sociedade e as instituições"6.

Wigdor e Magallanes (2018) explicam que o movimento pode ter sido inspirado no texto The Legal Subjection of Men (1908), de Ernest Belfort Bax, cuja escrita fora motivada pelo texto Legal Subjection of women (1869), de John Stuart Mill. Outros autores, como Germain Dulac (1993), remontam a trajetória dos defensores da causa masculina ao contexto da revolução sexual, como reação ao feminismo radical contemporâneo e aos avances políticos e sociais do Movimento de Liberação das Mulheres. Para Vigoya (2007, p. 29), as discussões sobre a chamada "crise das masculinidades" surgiu capitaneada por "autores que buscaram compreender os efeitos dos questionamentos feministas na identidade masculina"7.

Com base em outras pesquisas, Vigoya (1998) explica que os estudos em torno das masculinidades ampliaram seus tópicos e passaram a focalizar outras pautas, como foi o caso do questionamento do direito à paternidade; saúde sexual e reprodutiva; e a obrigatoriedade do homem no serviço militar. O autor de The Myth of Male Power, Warren Farrell, problematiza, por exemplo, imposições que fazem o homem ter um papel descartável na sociedade.

Do Movimento focalizado, surgem diferentes organizações. Pelo mundo, existe a $A$ Voice for Men - $A V f M$, que, depois de passar por reformulações, autodenomina-se Movimento por Direitos Humanos de Homens e Meninos - MDHHM. Com 9 representações oficiais - no início do site podemos ver extensões divididas entre duas categorias, a saber, línguas e países: português, espanhol, inglês, farsi, hebraico; Itália, România, Índia, Suécia -, escolhemos para análise o portal brasileiro.

O discurso do MDHHM se desenvolve principalmente no âmbito da internet, em numerosos blogues e sítios web, evitando os espaços de produção e difusão institucionais, entendidos - segundo essa perspectiva - como esferas em que impera a ideologia feminista (KUNERT, 2017). Na rede, o administrador dos espaços digitais (blogue, página web) conserva o controle sobre os conteúdos, ao contrário do que poderia acontecer em meios tradicionais como rádio ou televisão, por exemplo, ensejando a manutenção de apenas um ponto de vista.

\footnotetext{
6 Do original: "[...] un mouvement social conservateur ou réactionnaire qui prétend que les hommes souffrent d'une crise identitaire parce que les femmes en général, et les féministes en particulier, dominent la société et ses institutions".

7 Do original: “[...] por autores que buscaron comprender los efectos de los cuestio-namientos feministas en la identidad masculina."
} 
O sentido do termo "masculinista" com o qual muito frequentemente se qualifica ao movimento em questão varia segundo épocas e territórios (DUPUISDÉRI 2009, p. 97-98). De qualquer forma, implica essencialmente o ponto de vista crítico à causa hominista. Salvo exceções ${ }^{8}$, os membros de MDHHM não se identificam com o apelativo "masculinista", como podemos ver em uma afirmação do editor do AVfM Brasil, publicada no portal sob o título de Entrevista do "masculinista" Aldir Gracindo (sublinhamos o uso de aspas em masculinista para marcar distanciamento):

Para começar, por clareza, eu não sou masculinista. Sou uma pessoa interessada em direitos humanos que defende também direitos dos homens e meninos e faço isso de forma ativa, escrevendo e editando um site e outras atividades. Alguns feministas vão dizer que somos masculinistas, alguns masculinistas vão dizer que somos feministas (AVfM, 2014) ${ }^{9}$.

Posteriormente, observa-se uma mudança no posicionamento de editor de AVfM em relação ao uso de "masculinismo", como podemos ver no trecho que segue:
Quando eu falo masculinismo, considero que essa palavra designa uma primeira etapa, ou primeira onda do movimento dos homens. Os ativistas por direitos humanos dos homens, como eu, são uma nova geração, um fenômeno, procedimento e abordagens bem diferentes da primeira onda. Há uma diferenciação básica. As diferenças são muitas, por isso, até por honestidade, clareza, eu não me identifico para ninguém como masculinista (AVfM, 2016) ${ }^{10}$.

No fragmento observamos uma apropriação do conceito, sendo usado com um novo valor, porque aparece reduzido à descrição de uma primeira etapa (já ultrapassada) do movimento dos homens. De qualquer maneira, entendemos que o ethos e a cenografia da AVfM Brasil projeta - apesar de suas especificações discursos condizentes com as pautas dos movimentos que centralizam o homem.

A seguir, uma imagem da apresentação do sítio web (Figura 1). Nossa análise se centraliza no item sobre nós, especificamente a aba missão. A ela soma-se a observação da página como um todo: suas imagens, links e proposição de artigos.

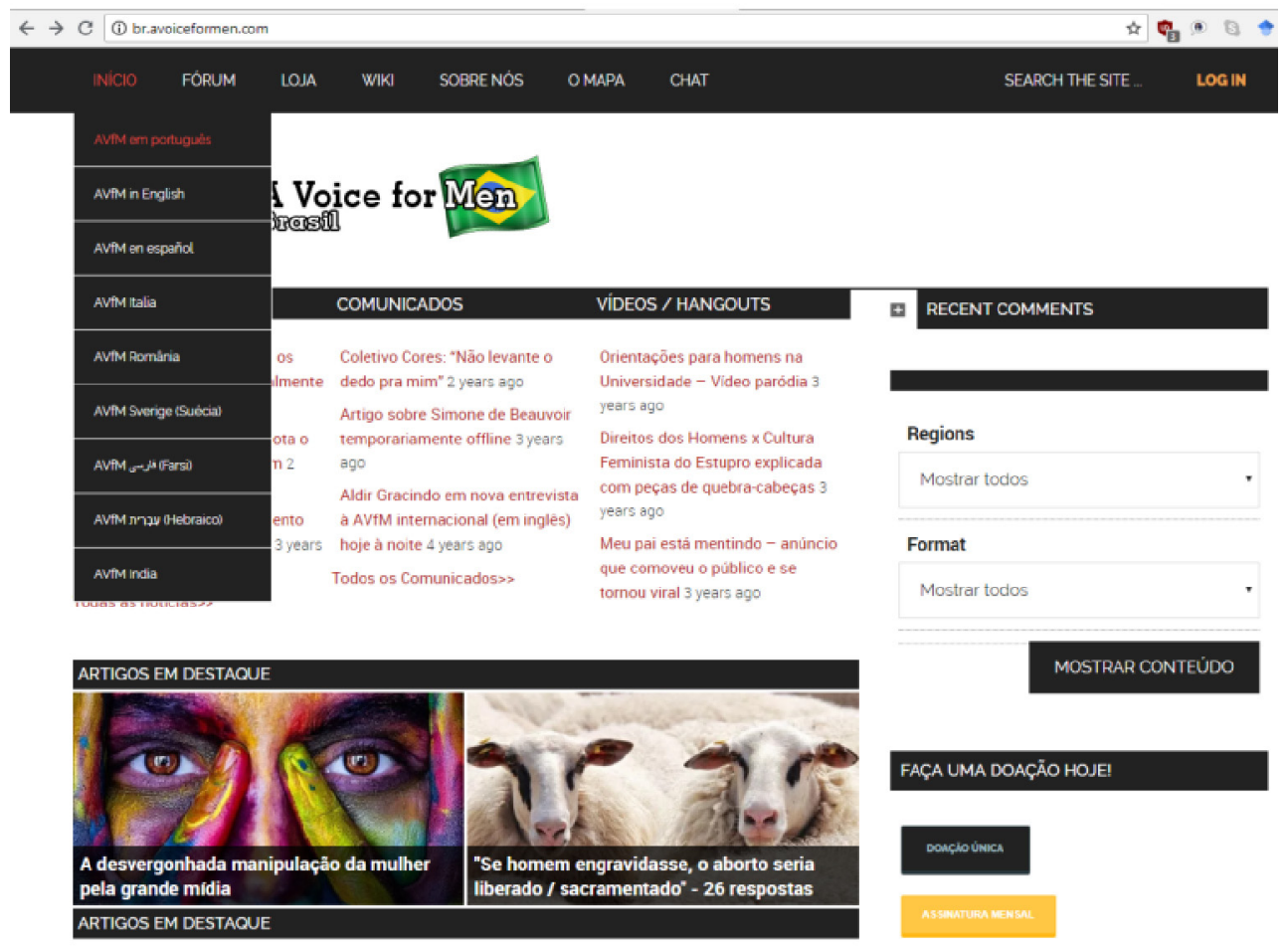

Figura 1. AVfM Brasil

Disponível em: <http://br.avoiceformen.com/>.

\footnotetext{
8 Por exemplo este vídeo apresentado no portal hispano de AVfM, em que o autor, Daniel Martínez, colaborador habitual do portal, assume o termo "masculinista", dando-lhe um novo valor baseado em "una perspectiva distinta, más empírica y más científica": <http://spa.avoiceformen.com/ hangouts/introduccion-al-feminismo-y-al-masculinismo/>. Acesso em jun. 2018
}

\footnotetext{
9 Disponível em: <http://br.avoiceformen.com/entrevista/entrevista-domasculinista-aldir-gracindo-a-marina-finco-estudante-de-jornalismo/>. Acesso em: jun. 2018.

${ }_{10}$ Disponível em: <http://br.avoiceformen.com/entrevista/entrevista-arobson-otto-aguiar-parte-2-final-feminismo-masculinismo-machismoesquerda-politica-avfm/>. Acesso em: jun. 2018.
} 
O AVfM é um portal aberto, porém, para ter acesso ao conteúdo integral, bem como ao fórum e ao chat a ele vinculados, é necessário estar conectado via cadastro com usuário e senha. A página é organizada, esteticamente sóbria, seus artigos são assinados pelos militantes, que vão desde pessoas ativamente presentes no cenário do movimento, a autores acadêmicos ou profissionais com formação superior que se envolvem com a causa. $\mathrm{Na}$ página, há espaço para diferentes tipos de arrecadação financeira, via doação, contribuição mensal ou a partir de compras de produtos personalizados.

Notamos, por isso, que se trata de um endereço eletrônico com investimento de manutenção, o que caracterizaria um site profissional, não apenas um fórum ou um blogue amador. Isso valida uma imagem discursiva de profissionalidade, que suscita engajamento porque oferece conteúdo respaldado por argumentos de autoridade: os artigos apresentam biografia que sempre informa o grau de formação e a área de atuação, links para os textos originais, links para plataformas reconhecidas (TEDx). Tal estratégia cria uma cenografia didática que atesta a missão de informar, promover conhecimento e ser uma fonte confiável de orientação aos partidários do conteúdo do site, tal como podemos ler na transcrição que segue:

É missão do A Voice for Men - Uma Voz para os Homens:

Promover a disseminação de informação que exponha a misandria e o gênero-centrismo em todos os níveis da nossa cultura;

Se opor a qualquer forma de gênero-centrismo. Nos propomos a avançar a igual valorização de homens e mulheres socialmente, a despeito da sexualidade ou identidade sexual, assim como o tratamento igual perante a lei;

Reconhecer a instituição do casamento e da unidade familiar como fundação da sociedade civilizada. No entanto, nós apoiamos a tendência ao afastamento dessa instituição até que o status legal que torna isso um risco para os homens e as crianças seja corrigido. Nós apoiamos o fim de leis de divórcio discriminatórias e apoiamos a igualdade parental na guarda, deveres e obrigações caso ocorra o divórcio. Nós buscamos promover conscientização e informação para proteger os homens e pais que atualmente casados.

Promover a rejeição do cavalheirismo com base em discriminação sexual em qualquer de seus aspectos;

Promover a oposição, não violenta e dentro da lei, a todos os agentes de misandria e gênero-centrismo, desde os membros do meio acadêmico, passando por gestores públicos, agentes da segurança pública e outros servidores estatais, até blogueiros(as) populares e colaboradores de empresas que promovam a misandria e gênero-centrismo para lucro pessoal;
Informar homens, mulheres, meninos e meninas sobre as ameaças que eles enfrentam onde houver ingerência do feminismo de gênero, e promover o fim dessa ingerência;

Desmascarar mentiras sexistas onde quer que elas ocorram;

Oferecer uma perspectiva mais razoável, cogente e intelectualmente honesta de políticas em questões de gênero;

Abordar a variedade de problemas enfrentados por homens e meninos sob ingerência feminista de gênero e tentar reduzir esses problemas;

Promover um fim para a histeria causada pela campanha da "cultura do estupro", informações falsas sobre violência doméstica e falsas acusações;

Promover uma cultura que valorize o tratamento igual perante a lei a todos os seres humanos;

Facilitar um novo contrato social entre homens e mulheres, levando a respeito mútuo, responsabilidade e expectativas igualitárias e justas;

O AVfM tem como única ideologia a compaixão por meninos e homens. Igualmente a meninas, mulheres e qualquer outro grupo humano (AVfM, BRASIL, 2014) $)^{11}$

$\mathrm{Na}$ tensão dos elementos postos no item que analisamos, é possível ver que o site encontra-se, em linhas gerais, no escopo do que é o Masculinismo, e, de modo específico, no que o site chama de Movimento por Direitos Humanos dos Homens e Meninos cujo objetivo é rever direitos "negligenciados por séculos de cultura ginocêntrica e, mais recentemente, corroídos por décadas de ingerência feminista" (AVfM, 2014) ${ }^{12}$. Mesmo que não tenha sido usada a palavra em si - Masculinismo -, o ethos discursivo que se projeta é o de combate à "ingerência feminista". No texto, vemos que é projetada nesse ethos a relação feminista $=$ misandria, fomentando o conteúdo implícito de que quem é feminista cultiva o ódio ao masculino. Esse ato leva à criação de uma identidade tanto para o grupo que veicula conteúdo na AVfM quanto para as feministas. Em assim sendo, sublinha a tensão existente entre ambos, demarcando posicionamentos binários.

Em "Promover a disseminação de informação que exponha a misandria e o gênero-centrismo em todos os níveis da nossa cultura", vemos valoração de combate (vide relação com outros usos ao longo do texto, tais como "oposição", "ingerência do feminismo") porque misandria projeta o sentido de ódio, desprezo ou preconceito pelo sexo masculino. Ocorre que essa

\footnotetext{
11 O Copyright tem registro de 2014.

12 Disponível em: <http://br.avoiceformen.com/recomendados/bem-vindoa-segunda-onda-o-movimento-por-direitos-humanos-dos-homens-emeninos/>. Acesso em: jun. 2018.
} 
valoração edifica uma contradição que marca o ethos projetado e o produzido. Isso porque, se existe por parte do grupo o combate ao gênero-centrismo, esse ethos é contradito no próprio discurso já que a sintaxe do trecho "O AVfM tem como única ideologia a compaixão por meninos e homens. Igualmente a meninas, mulheres e qualquer outro grupo humano" (grifos nossos) topicaliza a questão masculina, usa o adjetivo único para marcar essa valoração pró-homem e a corrobora com ponto final, indicando a argumentação definitiva daquela construção.

Ainda que o discurso seja continuado com "Igualmente a meninas, mulheres e qualquer outro grupo humano", essa extensão pode ser vista como um anexo para salvaguardar o grupo de possíveis críticas em relação ao fato de ser esse grupo um propositor do gênerocentrismo, nesse caso, o masculino. Essa continuação tem caráter generalizador, uma vez que coloca mulheres e meninas em relação a qualquer grupo humano. Os homens estão aquém desse conjunto "grupo humano"? A construção que vemos pode ser entendida como um discurso intimidatório porque é uma prática discursiva que deixa ver uma teia de relações gramaticais, lexicais, pragmáticas e sociodiscursivas, potencialmente dirigida contra o público feminista.

O grupo diz buscar "igual valorização de homens e mulheres socialmente". É possível ver no texto missão que a ideia de igualdade aparece representada seis vezes: igualdade de valorização, tratamento igual, igualdade parental, responsabilidades e expectativas igualitárias, igualdade perante a lei, compaixão igualmente a meninas. Essa valoração de engajamento igualitário não é condizente com o ethos que podemos ver no site quanto analisado como um todo discursivo, já que o grupo é pró-homem, a julgar pelo próprio título caracterizador do grupo em âmbito digital "A Voice for Men - Uma Voz para os Homens". Dessa observação, apresentamos uma lista de palavras ordenadas por frequência (Anexo 1), da qual originamos a nuvem de palavras que segue (Figura 2). Duas palavras ganham destaque pela recorrência: promover e homens.

No tecer do próprio conteúdo da página, vemos que a voz de AVfM é única, isto é, há um ponto de vista monofônico ("uma voz para os Homens), ainda que haja diversidade de colaboradores convocados em publicações que se podem acessar diretamente via hiperlinks tanto no site quanto em outras plataformas. Trata-se, em definitiva, de um simulacro de diálogo construído sobre uma espécie de monólogo sustentado por diferentes locutores em que a postura é sempre a mesma: sobre-enunciativa (posição enunciativa dominante; cf. RABATEL, 2012) em relação ao ponto de vista feminista cuja "misandria" denunciam.

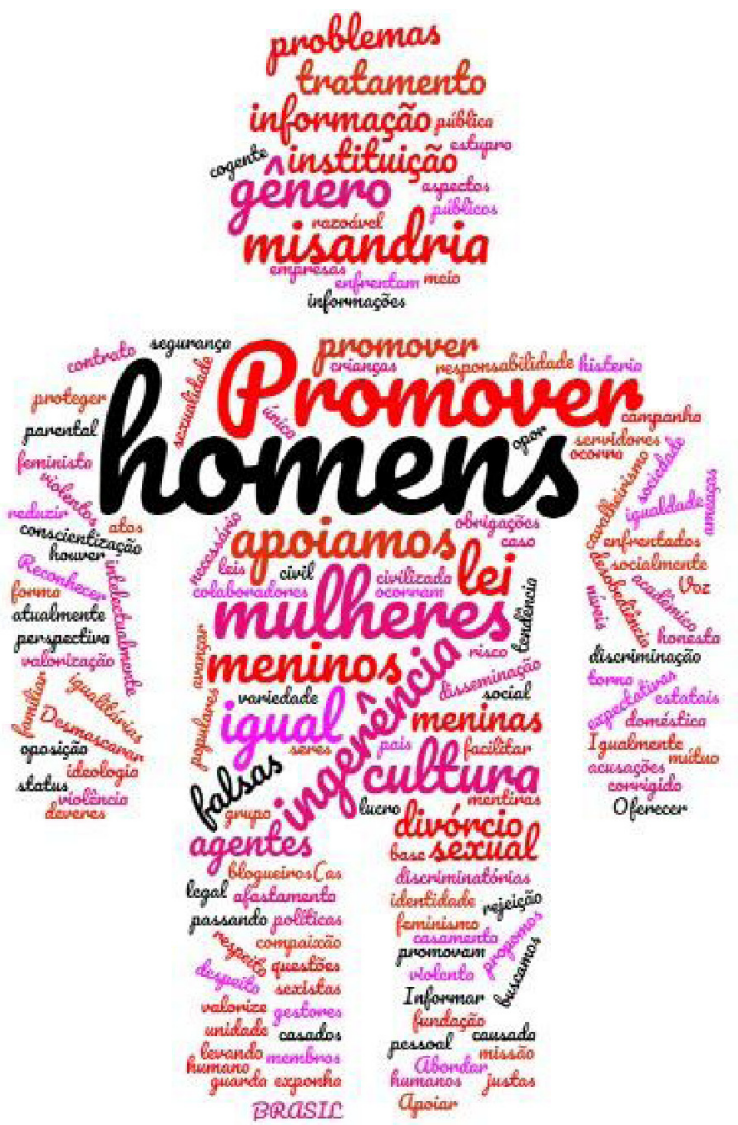

Figura 2. Nuvem de palavras criada a partir da frequência de uso

Fonte: Os autores.

Assim, entendemos que AVfM postula uma hegemonia feminista frente a qual se posicionam como um contrapúblico subordinado, hasteando - a partir de estratégias discursivas destinadas a provocar a compaixão das vítimas do feminismo e a adesão do leitor (homem ou mulher) por sua causa - o discurso sobre o direito de pais divorciados e de homens maltratados. Esse cenário configura uma defesa de causa baseada em contra-argumentos, favorecendo a polarização de posicionamentos em vez da igualdade que pretendem salvaguardar.

A política editorial também contradiz o ethos de combate ao gênero-centrismo porque há explicitamente a definição do grupo como pró-masculino ${ }^{13}$. Essa valoração pode ser vista também no contraste entre elementos verbais e visuais nas publicações, tal como apresentado na Figura 3.

\footnotetext{
3 "A Voice for Men ("Uma Voz para os Homens") é: 1. Pró-masculino - Isso significa homens e meninos, como um grupo monolítico, sem consideração de raça, credo, cor, religião, falta de religião ou orientação sexual" (AVfM, BRASIL, 2014). Disponível em: <http:// br.avoiceformen.com/politica-editorial/>. Acesso em jun. 2018
} 


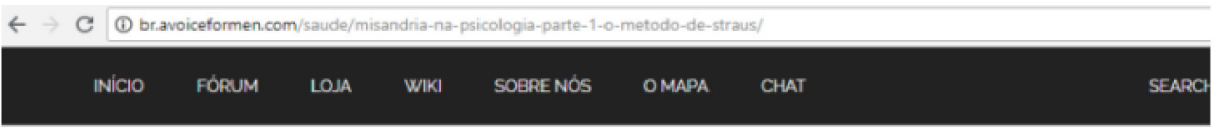

\section{$\boldsymbol{N}$ A $\mathrm{A}$ oice for Mond}

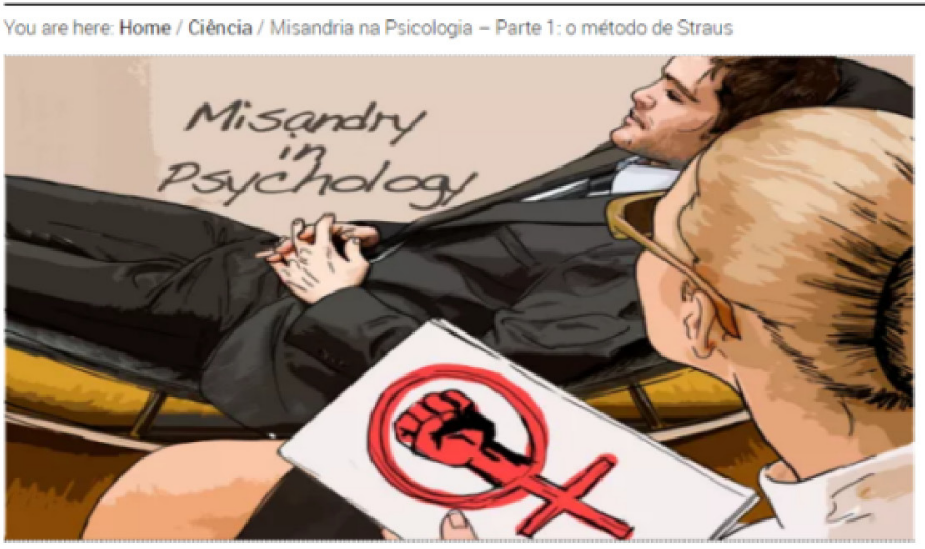

* RECENT COMM

Misandria na Psicologia - Parte 1: o método de Straus

May 12, 2014 by Tom Golden - 0 Comments

Esta e a primeira parte de uma serie de quatra artigos escritos pelo psicologa Tom Golden. Veja as demais partes parte 2 - parte 3 - Parte 4

Figura 3. Generalização da mulher como aquela que pratica misandria

Fonte: <http://br.avoiceformen.com/saude/misandria-na-psicologia-parte-1-o-metodo-de-straus/>

Nessa imagem podemos deduzir, primeiramente, que a psicóloga pratica misandria, a julgar pelo símbolo feminista nas mãos dela; o que fomenta os seguintes juízos de valor:

1. toda psicóloga é feminista;

2. a psicóloga é feminista porque é mulher;

3. ser mulher é ser misândrica.

Observamos também na imagem que mulher e homem estão em posições diferentes, ele deitado e ela sentada, indicando sobreposição, que marca tanto a autoridade paciente-terapeuta, quanto a superioridade da mulher em relação ao homem - o que na perspectiva do grupo seria a proposta feminista.

A valoração de engajamento contra o feminismo aparece na missão (combater a ingerência do feminismo), na política editorial ("[...] AVfM vê o feminismo como uma ideologia corrompida, de ódio, desonesta, baseada em elitismo feminino e misandria. E o AVfM considera todos os autodenominados feministas como agentes, inconscientes ou não, desse ódio e corrupção. [... $]^{14}$ )

\footnotetext{
${ }^{14}$ Disponível em: <http://br.avoiceformen.com/politica-editorial/>. Acesso em 30 de jun. 2018
}

e enfim nos materiais visuais veiculados (Figura 3 vista anteriormente e Figura 4, a seguir).

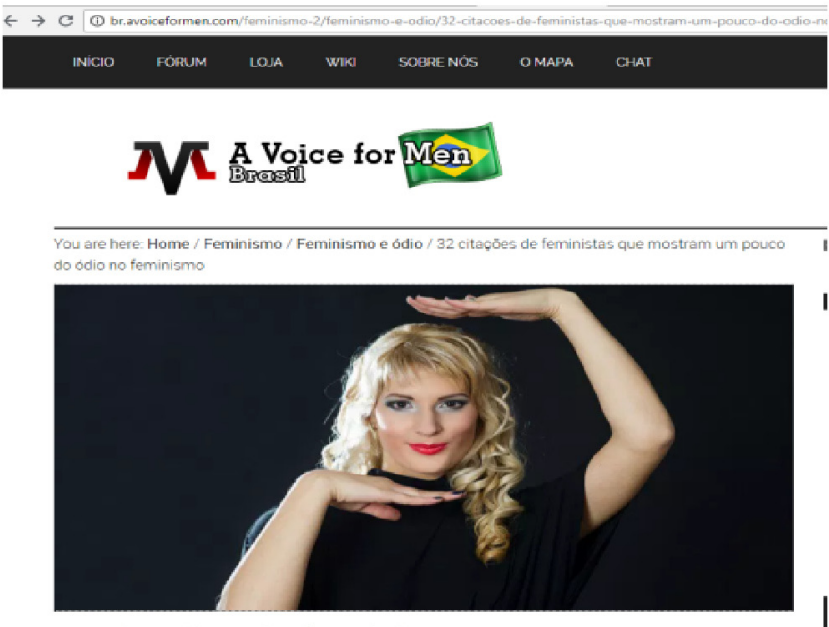

32 citações de feministas que mostram um pouco do ódio no feminismo

May a, 2016 Ey Aldr Gracindo - 10 Comments

Figura 4. Desqualificação da mulher feminista

Fonte: <http://br.avoiceformen.com/feminismo-2/feminismo-e-odio/ 32-citacoes-de-feministas-que-mostram-um-pouco-do-odio-no-feminismo/>. 
A publicação apresentada nessa figura constrói um ethos de desvalorização da mulher feminista, tanto pelos recursos verbais quanto não verbais. Do ponto de vista linguístico, o paralelo feministas-ódio deixa ver a valoração de parcialidade, agrupando, via ódio, feministas. $\mathrm{O}$ verbo mostram edifica com citações de feministas uma valoração de neutralidade porque não são os membros da AVfM que estão julgando as feministas, são elas mesmas que se deixam "mostrar" a partir da evidência contida em suas próprias falas. Essa construção cria a ideia de revelação, uma valoração de engajamento reiterada pelo grupo no texto missão ("desmascarar"; "Promover a disseminação de informação que exponha a misandria"). A desqualificação da mulher feminista ocorre nesse jogo linguístico porque cria a ideia de um movimento frágil, capaz de ser pego por seu próprio discurso. Constitui, pois, uma manobra de descontextualização e recontextualização do discurso feminista para que sirva aos fins do MDHHM.

Quando observamos os aspectos não verbais, dois pontos merecem destaque, a maquiagem e o gesto de mãos. Watikins et al. (2018) demonstrou em estudos de percepção - realizados com homens e mulheres - que a mulher com maquiagem forte possui uma valoração social negativa em relação às suas habilidades como líder. Os autores explicam que esse julgamento pode estar relacionado a uma imagem de que mulheres maquiadas em excesso são frívolas. Discorrendo sobre a representação da mulher, Benamsili (2014) menciona que os estereótipos femininos muitas vezes são construídos com base nas características que demarcam feminilidade, o que implica resgatar imagens de fertilidade, fragilidade e sensibilidade. Essa construção retira a mulher da condição de poder porque essas características associadas contrastam com estereótipos atribuídos aos homens, tais como força, masculinidade e racionalidade, importantes, por exemplo, no meio corporativo. Para Charaudeau (2007), os estereótipos não são nem verdadeiros nem falsos, são imaginários que deixam ver visões de mundo.

Escolher a fotografia de uma mulher maquiada com cores contrastantes institui uma argumentação baseada em estereótipos com a intenção de gerar conivência e aceitabilidade na relação web-destinatário. Isso significa dizer que o discurso que é tecido na trama entre verbal e não verbal está edificado para a desqualificação de tudo o que é ligado à mulher e ao feminismo. Valoração essa projetada tanto na cenografia do site como um todo quanto por quem dele é leitor/consumidor.

$\mathrm{O}$ gesto de mãos que forma uma figura quadrada ao redor da cabeça da mulher reitera essa valoração de desqualificação, pois pode indicar limitação, devido ao que a forma quadrada sugere em termos de linguagem.
Isso porque o uso, por exemplo, do qualificador quadrado, em língua portuguesa, projeta possibilidades de sentido de antiquado, anacrônico, atrasado, bronco, ignorante, deixando perceber uma valoração de limitação em relação à capacidade intelectual da mulher feminista.

Assim, na cenografia digital, é possível ver que o ethos de AVfM se manifesta nos textos, em sua organização e acessibilidade via hipervínculo com textos do mesmo portal ou de outros, bem como nas imagens oferecidas, que não somente ilustram, mas também significam por contiguidade e simetria com o discurso escrito, participando na cenografia global. As inferências realizadas a partir das imagens simultaneamente com a interpretação de texto nos servem para "clarificar o ethos" (SOULEZ, 2002, p. 198).

De modo geral, não há marcas explícitas ou signos do ethos, o que ocorre é a identificação resultante de um cálculo inferencial, um processo interpretativo baseado em estereótipos e clichés (AMOSSY; HERSCHBERGPIERROT, 2010), bem como em rotinas de linguagem (NEE; SITRI; VENIARD, 2016). Nesses termos, não há uma relação de causalidade entre certos empregos e um ethos específico, senão uma dinâmica de semelhanças e diferenças: um certo uso ou uma certa palavra/ expressão funcionam como detonante de uma implicatura, ao direcionar a hábitos ou comportamentos linguísticos conhecidos, a discursos já ditos ou ouvidos, mais ou menos repetidos. Como explica Amossy (1999, p.136): "cabe ao receptor formar uma impressão do locutor relacionando-a a uma categoria conhecida" 15 . Assim, apenas uma inferência não basta para identificar um ethos discursivo, o que o denuncia é a múltipla inferência que o interlocutor pode formar, construindo uma imagem mais ou menos estável do locutor, de modo a remeter, finalmente, a uma interpretação plausível.

\section{Considerações finais}

Dando continuidade ao debate sobre discursos de intimidação, colocando-se a tarefa de pensar como eles se apresentam na modalidade digital, este artigo analisou o endereço eletrônico A voice for Men Brasil - AVfM. Como resultados das análises, vimos que os sentidos se constroem na tensão entre o ethos desejado e o produzido, tendo sempre em consideração os elementos verbais e não verbais que compõem a cenografia. Todos esses aspectos devem ser considerados no processo de leitura, a fim de que seja possível ver as valorações que atravessam os discursos em circulação.

\footnotetext{
${ }^{15}$ Do original: "C'est au récepteur qu'il incombe de se former une impression de l'orateur en le rattachant à une catégorie connue".
} 
Os traços que caracterizam os aspectos analisados indicam discurso intimidatório para com o público feminista. Essa afirmação é projetada pelo próprio texto que marca a missão do grupo e é, sempre que oportuno, reiterada nas publicações do site. Na AVfM, essa dinâmica de contrários se manifesta também no uso recorrente de termos baseados na afirmação da causa masculina ("próliberdade de expressão", "pró-masculino", "pró-direitos reprodutivos masculinos") e no rechaço à negação de préconstruídos (antiviolência, antiproselitista, antifeminista, anticavalheirismo, não tradicionalista).

Para análise do repertório de termos recorrentes, usamos aplicações disponíveis na rede para contar palavras e elaborar nuvens. Os estudos quantitativos realizados destacam uma série de palavras e expressões que constroem um segundo discurso, em segundo plano em relação à igualdade de sexos, que aponta contrariamente à igualdade - uma defesa veemente do masculino e, inclusive, mais ou menos abertamente incita ao ódio em relação ao sexo feminino, e em concreto às feministas.

Não acreditamos que seja o caso de um lapso, posto que não se trate de um caso isolado. Assim, interpretamos como uma estratégia premeditada de construção de discurso discriminatório (ethos produzido) de forma sutil (implícita), a fim de que seja preservada a cara positiva do grupo (BROWN; LEVINSON, 1978), evitando denúncias e acusações indesejadas. Além disso, serve para mostrar ao leitor que lê superficialmente um ethos de moderação (ethos desejado).

Como vimos, há uma série de estratégias de legitimação por parte daqueles que alimentam os conteúdos do site analisado. $\mathrm{O}$ discurso da causa masculina busca racionalização e credibilidade, conjugando convenientemente um ethos social coletivo profissional qualificado (intelectuais, jornalistas, psicólogos, economistas, etc.) a partir da exploração de uma retórica aparentemente igualitária.

Há repertório de argumentos recorrentes: os argumentos de causa masculina se baseiam na inversão, distorção ou fagocitação dos argumentos feministas. A argumentação se baseia em uma contra-argumentação, no marco geral de uma estratégia de construção de um ponto de vista antagônico que se manifesta por meio de um ethos discursivo de contrapúblico minoritário subordinado em relação ao grupo feminista supostamente dominante (FRASER, 1992). Os argumentos da causa masculina têm como objetivo desmontar a ideologia feminista utilizando principalmente contra-argumentos, com os quais ao final não conseguem senão perpetuar a polarização dos posicionamentos na histórica controversa dos gêneros, em vez da igualdade que pretendem promover.

\section{Referências}

AMOSSY, Ruth; PIERROT, Anne Herschberg. Estereótipos y clichés. Buenos Aires: Eudeba, 2010.

AMOSSY, Ruth; PIERROT, Anne Herschberg. La présentation de soi - Ethos et identité verbale. Paris: PUF, 2010.

AMOSSY, Ruth; PIERROT, Anne Herschberg. L'éthos au carrefour des disciplines: réthorique, pragmatique, sociologie des champs. In: AMOSSY, Ruth (Dir.). Images de soi dans le discours. Lausanne-Paris: Delachaux-Nieslé, 1999.

BAKHTIN, Mikhail. Para uma filosofia do ato responsável [1920-24]. São Carlos: Pedro e João, 2012.

BENAMSILI, Sonia. Les stéréotypes de la femme dans la caricature de Dilem Ali. Corela, v. 12, n. 1, 2014.

BONNAFOUS, Simone; KRIEG-PLANQUE, Alice. L'analyse du discours. In: OLIVESI, Stéphane (Dir.). Sciences de l'information et de la communication. Objets, savoirs, discipline. Grenoble: Presses Universitaires de Grenoble, 2013. (Coll. La communication en plus). 302p.; p. 223-238.

BROWN, Penelope; LEVINSON, Stephen. Universals in Language Usage: Politeness Phenomena. In: GOODY, E. N. [Ed.]. Questions and Politeness: Strategies in Social Interaction. Cambridge: Cambridge University Press, 1978. p. 56-311.

CHARAUDEAU, Patrick. Les stéréotypes, c'est bien. Les imaginaires, c'est mieux. In: BOYER, Henri. Stéréotypage, stéréotypes, fonctionnements ordinaires et mises en scène. Paris: L'Harmattan, 2007.

CHARAUDEAU, Patrick. Identité sociale et identité discursive. Un jeu de miroir fondateur de l'activité langagière. In: Identités sociales et discursives du sujet parlant. Paris: L'Harmattan, 2017.

CHARAUDEAU, Patrick; MAINGUENEAU, Dominique. Dicionário de análise do discurso. São Paulo: Contexto, 2018.

DEZERTO, Felipe Barbosa. Da Linguística Formal à Analise do Discurso: um breve percurso teórico. In: Veredas (online) Análise do Discurso, Juiz de Fora, v. 2, p. 64-79, 2010.

DULAC, Germain. Penser le masculin. Essai sur la trajectoire des militants de la condition masculine et paternelle. Québec: IQRC/PUL, 1993.

DUPUIS-DÉRI, Francis. Le "masculinisme": une histoire politique du mot (en anglais et en français). Recherches féministes, v. 22, n. 2, p. 97-123, 2009. Disponível em: <https:// www.erudit.org/fr/revues/rf/2009-v22-n2-rf3635/039213ar. pdf $>$. Acesso em: maio 2018. DOI: 10.7202/039213ar

FERNÁNDEZ SMITH, Gérard. Instrumentos linguísticos de los discursos de odio en la prensa digital. In: Fragmentum, Santa Maria: Programa de Pós-Graduação em Letras, UFSM, n. 50, jul./dez. 2017. ISSN 2179-2194 (online); 1519-9894 (impresso).

FRASER, Nancy. Repenser la sphère publique: une contribution à la critique de la démocratie telle qu'elle existe réellement. In: CALHOUN, Craig (Dir.). Habermas and the Public Sphere. Cambridge: MIT Press, 1992. p. 109-142.

KUNERT, Stéphanie. Discursive Configurations and Legitimization Strategies of 'the Men's Cause. Etudes de communication - Langages, information, médiations, Université Lille-3, 2017. p.91-110. 
LÓPEZ-MUÑOZ, Juan Manuel; CAPPONI, Paola. Los discursos intimidatorios: ¿de dónde vienen y adónde van? In: Fragmentum, Santa Maria, Programa de Pós-Graduação em Letras, UFSM, n. 50, jul./dez. 2017.

MAINGUENEAU, Dominique. Análise de textos de comunicação. São Paulo: Cortez, 2004.

MAINGUENEAU, Dominique. Novas tendências em Análise do Discurso. São Paulo: Pontes, 1997.

NÉE, Émilie, Frédérique SITRI; Marie VENIARD. Les routines, une catégorie pour l'analyse de discours: le cas des rapports éducatifs, Lidil, v. 53, p. 71-93, 2016.

PAVEAU, Marie-Anne. L'analyse du discours numérique. Paris: Hermann, 2015.

PAVEAU, Marie-Anne. Quelles données entre l'esprit et le discours? Du préconstruit au prédiscours. In: HAL: L'analyse du discours - Notions et problèmes, Les éditions Sahar, Reims, France, p. 19-37, 2011. Disponível em: <https://hal.archivesouvertes.fr/hal-00596737>. Acesso em: maio 2018.

PAVEAU, Marie-Anne. Mais où est donc le sens? Pour une linguistique symétrique. In: $H A L$ : Res per nomen 2, Reims, France, p.21-31, May 2009. Disponível em: <https://hal. archives-ouvertes.fr/hal-00477257>. Acesso em: maio 2018.

RABATEL, Alain. Positions, positionnements et postures de l'énonciateur, Travaux Neuchatelois de Linguistique TRANEL, 201656, 2012. p. 23-42.
SOULEZ, Guillaume. Ethos, énonciation, média. Sémiotique de l'éthos, Recherches en communication, p. 175-198, 2002.

SOUSA, Pedro de. Análise de Discurso. Florianópolis: UFSC, 2014.

VENTURINI, Maria Cleci; SCHERER, Amanda Eloína. O discurso do/sobre ódio no contexto brasileiro: nosso compromisso político com o dizer. In: Fragmentum, Santa Maria, Programa de Pós-Graduação em Letras, UFSM, n. 50, jul./dez. 2017.

VIGOYA, Mara Viveros. Teorías feministas y estudios sobre varones y masculinidades. Dilemas y desafíos recientes. In: $\mathrm{La}$ manzana de la discordia, año 2, n. 4, p. 25-36, dic. 2007.

VOLÓCHINOV, Valentin. Marxismo e filosofia da linguagem. São Paulo: Ed. 34, 2017.

WEST, Robin. Género y teoría del Derecho. Santa fé de Bogotá: Siglo del Hombre, 2000.

WATIKINS, Chistopher D. et al. Negative Effects of Makeup Use on Perceptions of Leadership Ability Across Two Ethnicities. (2018). Disponível em: <http://journals.sagepub.com/doi/ full/10.1177/0301006618763263>. Acesso em: jun. 2018.

WIGDOR, Bard, G.; MAGALLANES, M. L. El Masculinismo Hetero-Hegemónico Argentino y su Estrategia desde el Ciberactivismo. In: Masculinities and Social Change, v. 7, n. 1, p. 25-51, 2018.

\section{ANEXO 1}

$\begin{array}{ll}8 & \text { homens } \\ 5 & \text { Promover } \\ 4 & \text { gênero-entrismo } \\ 4 & \text { mulheres } \\ 3 & \text { ingerência } \\ 3 & \text { misandria } \\ 3 & \text { apoiamos } \\ 3 & \text { meninos } \\ 3 & \text { cultura } \\ 3 & \text { gênero } \\ 3 & \text { igual } \\ 3 & \text { lei } \\ 2 & \text { instituição } \\ 2 & \text { tratamento } \\ 2 & \text { informação } \\ 2 & \text { problemas } \\ 2 & \text { divórcio } \\ 2 & \text { promover } \\ 2 & \text { agentes } \\ 2 & \text { meninas } \\ 2 & \text { falsas } \\ 2 & \text { sexual } \\ 1 & \text { responsabilidade } \\ 1 & \text { intelectualmente } \\ 1 & \text { discriminatórias } \\ 1 & \text { conscientização } \\ 1 & \text { blogueiros(as) } \\ 1 & \text { cavalheirismo } \\ 1 & \text { desobediência } \\ 1 & \text { discriminação }\end{array}$

$\begin{array}{ll}1 & \text { colaboradores } \\ 1 & \text { disseminação } \\ 1 & \text { expectativas } \\ 1 & \text { igualitárias } \\ 1 & \text { valorização } \\ 1 & \text { perspectiva } \\ 1 & \text { enfrentados } \\ 1 & \text { afastamento } \\ 1 & \text { Desmascarar } \\ 1 & \text { socialmente } \\ 1 & \text { sexualidade } \\ 1 & \text { informações } \\ 1 & \text { atualmente } \\ 1 & \text { obrigações } \\ 1 & \text { necessário } \\ 1 & \text { Igualmente } \\ 1 & \text { civilizada } \\ 1 & \text { servidores } \\ 1 & \text { identidade } \\ 1 & \text { Reconhecer } \\ 1 & \text { doméstica } \\ 1 & \text { igualdade } \\ 1 & \text { tendência } \\ 1 & \text { acadêmico } \\ 1 & \text { segurança } \\ 1 & \text { variedade } \\ 1 & \text { acusações } \\ 1 & \text { ideologia } \\ 1 & \text { sociedade } \\ 1 & \text { enfrentam }\end{array}$

1 violentos

1 políticas

1 populares

1 feminismo

1 corrigido

1 violência

1 feminista

1 casamento

1 compaixão

1 facilitar

1 parental

1 passando

1 oposição

1 promovam

1 histeria

1 proteger

1 rejeição

1 Oferecer

1 campanha

1 estatais

1 questões

1 razoável

1 respeito

1 familiar

1 violenta

1 sexistas

1 empresas

1 propomos

1 Informar

1 contrato

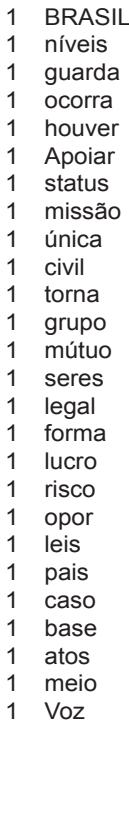

1 BRASIL

despeito

públicos

1 mentiras

gestores

fundação

1 buscamos

1 crianças

aspectos

1 valorize

1 membros

reduzir

casados

1 pessoal

1 unidade

ameaças

1 deveres

1 causada

cogente

1 avançar

1 Abordar

1 levando

1 estupro

ocorram

1 exponha

1 pública

1 humanos

1 honesta

1 social

1 humano

1 justas

Recebido: 20/05/2018

Aprovado: 16/09/2018

(D) JUAN MANUEL LÓPEZ-MuÑOZ <jmanuel.lopez@uca.es> Professor, Universidad de Cádiz, Cádiz, Espanha.

(D) TAMIRIS MACHADO GONÇALVES <mtamiris@gmail.com>

Doutoranda, Pontifícia Universidade Católica do Rio Grande do Sul, Porto Alegre,

Rio Grande do Sul, Brasil. 